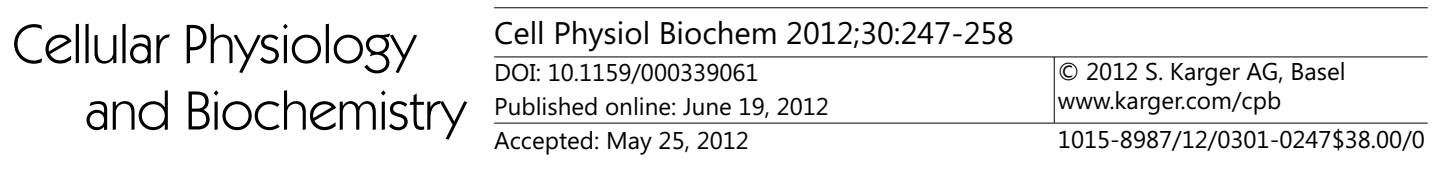

\title{
cAMP Induces Adhesion of Microvascular Smooth Muscle Cells to Fibronectin via an Epac-Mediated but PKA-independent Mechanism
}

\author{
Ali H. Eid \\ Department of Biological and Environmental Sciences, Qatar University, Doha, Qatar
}

Key Words

Cyclic AMP • Vascular smooth muscle $\bullet$ Cell adhesion

\begin{abstract}
Background/Aims: Vascular smooth muscle cells (VSMCs) play important roles, both in physiologic and pathophysiologic processes. Adhesion of these cells is critical for their proper functioning, especially in resistance-sized vessels. Nonetheless, very little is known about mechanisms regulating adhesion of VSMCs. In particular, the role of CAMP and its downstream effectors, PKA and Epac, remain poorly investigated. Methods: Primary cultured cells were isolated from human dermal arterioles and adhesion to fibronectin measured. Adhesion assay was performed in the presence or absence of cAMP elevating agents and activators or inhibitors of PKA or Epac signaling. Results: cAMP increases adhesion of microvascular smooth muscle cells to fibronectin in concentration and time-dependent fashions. Pretreatment with $\mathrm{H} 89$, a PKA inhibitor, did not affect the adhesion, indicating a PKA-independence of the induced adhesion. Selective activation of PKA did not affect adhesion, whereas selective activation of Epac (by 8-pCPT-2'-O-Me-cAMP) increased adhesion. Moreover, expression of a dominant negative mutant of Epac abolished the induced adhesion. CAMP elevation by a physiologic agonist, isoproterenol, mimicked the results obtained with forskolin or 8-pCPT-2'-O-Me-cAMP. Blocking $\beta 1$ integrins abrogated the induced adhesion. Conclusion: The results of this study demonstrate for the first time that CAMP induces adhesion of human microvascular smooth muscle cells to fibronectin via $\beta 1$ integrins. This adhesion appears to be mediated by Epac, independently if PKA.

Copyright @ 2012 S. Karger AG, Basel
\end{abstract}

\section{Introduction}

Vascular smooth muscle cells (SMCs) play vital roles in vascular tone and resistance, as well as formation and repair of blood vessels [1]. These functions require tight regulation of the VSMC contractile or synthetic/migratory phenotype. In either phenotype, adhesion 


\begin{tabular}{rl|l} 
Cellular Physiology & \begin{tabular}{l} 
Cell Physiol Biochem 2012;30:247-258 \\
\cline { 2 - 2 } DOI: 10.1159/000339061
\end{tabular} & \\
and Biochemistry & $\begin{array}{l}\text { Published online: June 19, 2012 } \\
\text { www.karger.com/cpb }\end{array}$ \\
\cline { 2 - 3 } Eid: Epac and Adhesion of Vascular Smooth Muscle Cells
\end{tabular}

of vascular SMCs to their extracellular matrix (ECM) is critical. A strong adhesion ensures that vascular SMCs are capable of withstanding substantial tension which results from contraction or hemodynamic forces [2]. A well-controlled balance between contraction and relaxation is vital for the maintenance of a homeostatic blood flow and pressure. A better understanding of mechanisms that regulate adhesion of SMCs is essential, particularly for resistance-sized arterioles since a small change in their diameter precipitates dramatic and potentially disastrous effects.

Cells regulate their adhesion based on internal and external signaling cues. A key signaling molecule that plays significant roles in various cellular phenotypes is cAMP. One function of cAMP is modulation of integrin-mediated cell adhesion. Depending on the cell type and context, cAMP may either stimulate or inhibit cell adhesion. For example, an increase in intracellular cAMP levels inhibits adhesion of mature T lymphocytes to fibronectin [3], prevents leukocyte adhesion in response to chemoattractants [4], enhances adhesion of immature thymocytes to fibronectin [5] or promotes integrin-mediated adhesion of endothelial cells to fibronectin [6]. In vascular SMCs of large vessels, binding to fibronectin modulates nitric oxide, cGMP and protein kinase G signaling [7] , all of which are key elements in vasodilatory mechanisms. Whether cAMP regulates adhesion of arteriolar smooth muscle cells remains poorly investigated. Here we determine the role of cAMP in the adhesion of SMCs isolated from human arterioles.

For many years, cAMP was thought to mediate its effects only via protein kinase A (PKA). Recently, however, it was shown that cAMP can elicit its effects by activating guanine nucleotide exchange factors (GEFs) in a PKA-independent fashion [8, 9]. GEFs are proteins that catalyze the dissociation of GDP from intracellular GTPases allowing the more available GTP to bind to and activate these GTPases. Epac (exchange protein directly activated by cAMP) is a widely expressed GEF that mediates many of cAMP effects. We recently showed that Epac is expressed in human arteriolar smooth muscle cells, and that cAMP can activate both PKA and Epac in these cells [10-12]. However, the roles of PKA and Epac in the adhesion of these cells in not known. This study was therefore undertaken to elucidate these roles.

\section{Materials and Methods}

Materials and Plasmids

Forskolin, isoproterenol, and fibronectin were obtained from Sigma Chemical Co. (St. Louis, MO, USA), H89 from CalBiochem (San Diego, CA, USA) and cAMP-analogue 8-(4-Chlorophenylthio)-2'-0methyladenosine 3',5'-cyclic monophosphate from Axxora (San Diego, CA, USA). pCMV-enhancer-luciferase was purchased from Promega (Madison, WI). The expression plasmids of Epac were a kind gift from Dr. Xiaodong Cheng (Department of Pharmacology and Toxicology; University of Texas Medical Branch; Galveston, Texas) and was generated as previously described [13].

Human Vascular Smooth Muscle Cell (SMC) Culture

As we previously described $[10,11]$, vascular SMCs were cultured from human dermal arterioles isolated from upper arm skin punch biopsies (4-6 mm) from normal healthy donors. Only cells of passages 9-12 were used. All cultures were confirmed to be at least $99 \%$ pure by fluorescence-activated cell sorting analysis for the expression of $\alpha$-actin and basic calponin [14]. As previously described [10, 11], cells were grown in Ham's Growth medium (DMEM:F12, 50:50; supplemented with 10\% heat inactivated FBS, LGlutamine, and an antibiotic/antimycotic cocktail). Cells were routinely maintained in a humidified $37^{\circ} \mathrm{C}$ incubator with $5 \% \mathrm{CO}_{2}$.

Transient Transfections

Cells were transfected by nucleofection (Lonza, MD, USA) according to the manufacturer's protocol $[10,11]$. Cells were then allowed to recover overnight in Ham's growth medium. Transfection was optimized to achieve approximately $80 \%$ efficiency, with minimal toxicity. Transfection efficiency was assessed by the use of a green fluorescent protein (GFP). The total amount of transfected plasmids was kept the same throughout the experiments. 


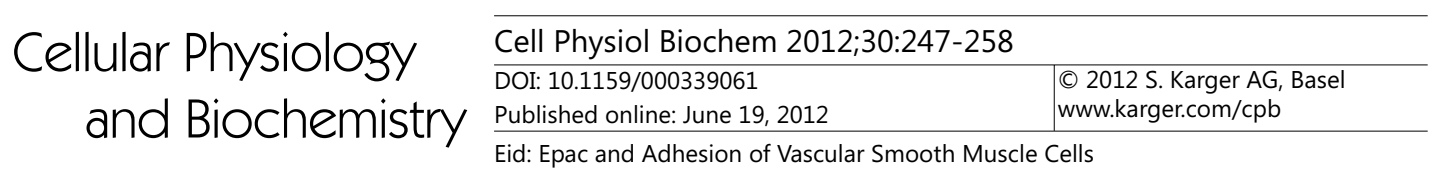

Adhesion Assay

Cells were transfected with a PGL3 enhancer-luciferase vector and allowed to recover in Ham's growth medium for 18 hours. Cells were then made quiescent by incubating them in serum-free medium for 48 hours before any treatments. After cells were detached by trypsinization, they were centrifuged at $1000 \mathrm{~g}$ for 5 minutes and resuspended in serum-free medium containing 25 mM HEPES, 0.5\% Bovine Serum Albumin (BSA), and $1 \mathrm{~g} / \mathrm{L}$ glucose to allow for the recovery of cell surface markers, at $37^{\circ} \mathrm{C}$ for 1.5 hours with gentle rotation in suspension. Cells were then centrifuged and resuspended in serum-free medium with $0.5 \%$ BSA, and seeded into Fibronectin-coated 6-well plates. For long treatment with H89, it was added to cells before trypsinization, during the recovery period as well as during the seeding process. For short treatment, H89 was added during the seeding process and cells incubated thereafter.

Plates were coated overnight with fibronectin $(2 \mu \mathrm{g} / \mathrm{ml})$ in sodium bicarbonate buffer. Plates were then washed in TSM buffer ( $20 \mathrm{mM}$ Tris- $\mathrm{HCl}, \mathrm{pH} 8.0,150 \mathrm{mM} \mathrm{NaCl}, 1 \mathrm{mM} \mathrm{CaCl}, 2 \mathrm{mM} \mathrm{MgCl}_{2}$ ) and blocked for 45 minutes at $37^{\circ} \mathrm{C}$ with $1 \% \mathrm{BSA} / \mathrm{TSM}$.

Treatment sets were performed in triplicates. Cells were allowed to adhere for 1 hour at $37^{\circ} \mathrm{C}$ (unless mentioned otherwise), and non-adherent cells were removed by very gently washing plates three times with pre-warmed 0.5\% BSA/TSM. Adherent cells were lysed in luciferase lysis buffer (Promega, Madison, WI) and relative light units were measured as per the manufacturer's protocol (Promega). Non-seeded cells were separately lysed to determine the total light units in the input cells. Specific adhesion is determined as 100 times the units of cells adhering divided by the total input.

\section{Statistical Analysis}

Statistical analysis of the data was performed by Student's t-test for either paired or unpaired observations using GraphPad Prism version 5.0 and InStat3 Software (GraphPad software, Inc. San Diego, CA). Data is presented as mean $\pm S E M$, where $n$ is equal to the number of different cell culture experiments.

\section{Results}

cAMP promotes adhesion of arteriolar SMCs to fibronectin via a PKA-independent mechanism

Forskolin, a potent adenylate cyclase activator, caused a significant increase in the adhesion of human arteriolar SMCs to fibronectin in a concentration- and time-dependent manner. Cells were incubated in the absence (vehicle) or presence of forskolin $(0-20 \mu \mathrm{M})$ for 60 minutes. Compared to vehicle, forskolin concentrations of $5 \mu \mathrm{M}$ or higher evoked a significant $(\mathrm{p}<0.05)$ increase in the adhesion of cells to fibronectin (Fig. 1A).

Treatment with forskolin $(10 \mu \mathrm{M})$ for different durations (30-120 minutes) demonstrated a time-dependent effect (Fig. 1B). Adhesion to fibronectin was significantly higher in the forskolin-treated compared to vehicle-treated cells $(11 \%$ vs $25 \%$ after 60 minutes, $n=3$; $\mathrm{p}<0.05$ and $18 \%$ vs $49.5 \%$ after 120 minutes, $\mathrm{n}=3$; $\mathrm{p}<0.001$ ). Interestingly, pre-treatment with the PKA inhibitor H89 $(5 \mu \mathrm{M})$ did not modulate forskolin-induced adhesion $(25 \%$ vs $26 \%, \mathrm{n}=3, \mathrm{p}>0.05$ after 60 minutes; and $49.5 \%$ vs $55.7 \%, \mathrm{n}=3, \mathrm{p}>0.05$ after 120 minutes). Treatment with $\mathrm{H} 89$ alone also did not significantly affect adhesion at either timepoint $(n=3$; $p>0.05$ ). We recently reported that the used concentration of H89 is sufficient to inhibit PKA in vascular SMCs, evident by the reduced phosphorylation of PKA's target, CREB [12].

Duration of the $\mathrm{H} 89$ pre-treatment did not seem to affect the forskolin-induced adhesion. Indeed, pretreatment of cells with H89 before, during and after the recovery period (long) or only after the recovery period (short) did not affect the forskolin-induced adhesion on fibronectin (Fig. 1C). For short treatments, forskolin induced a 2.7- or 3- fold increase ( $n=3$; $\mathrm{p}>0.05$ ) in adhesion in the respective absence or presence of H89 (Fig. 1C). In separate experiments with long treatments, forskolin induced a 3.1- or 3.5- fold increase $(n=3$; p>0.05) in adhesion in the respective absence or presence of H89 (Fig. 1C). Taken together, these data suggest that cAMP promotes adhesion of arteriolar SMC via a PKA-independent mechanism. 


\section{Cellular Physiology Cell Physiol Biochem 2012;30:247-258

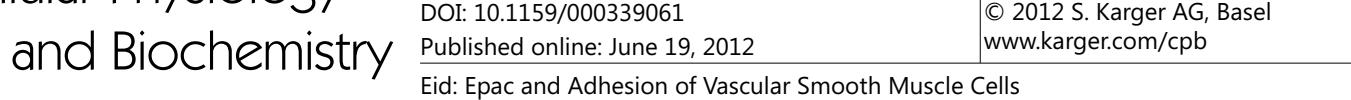

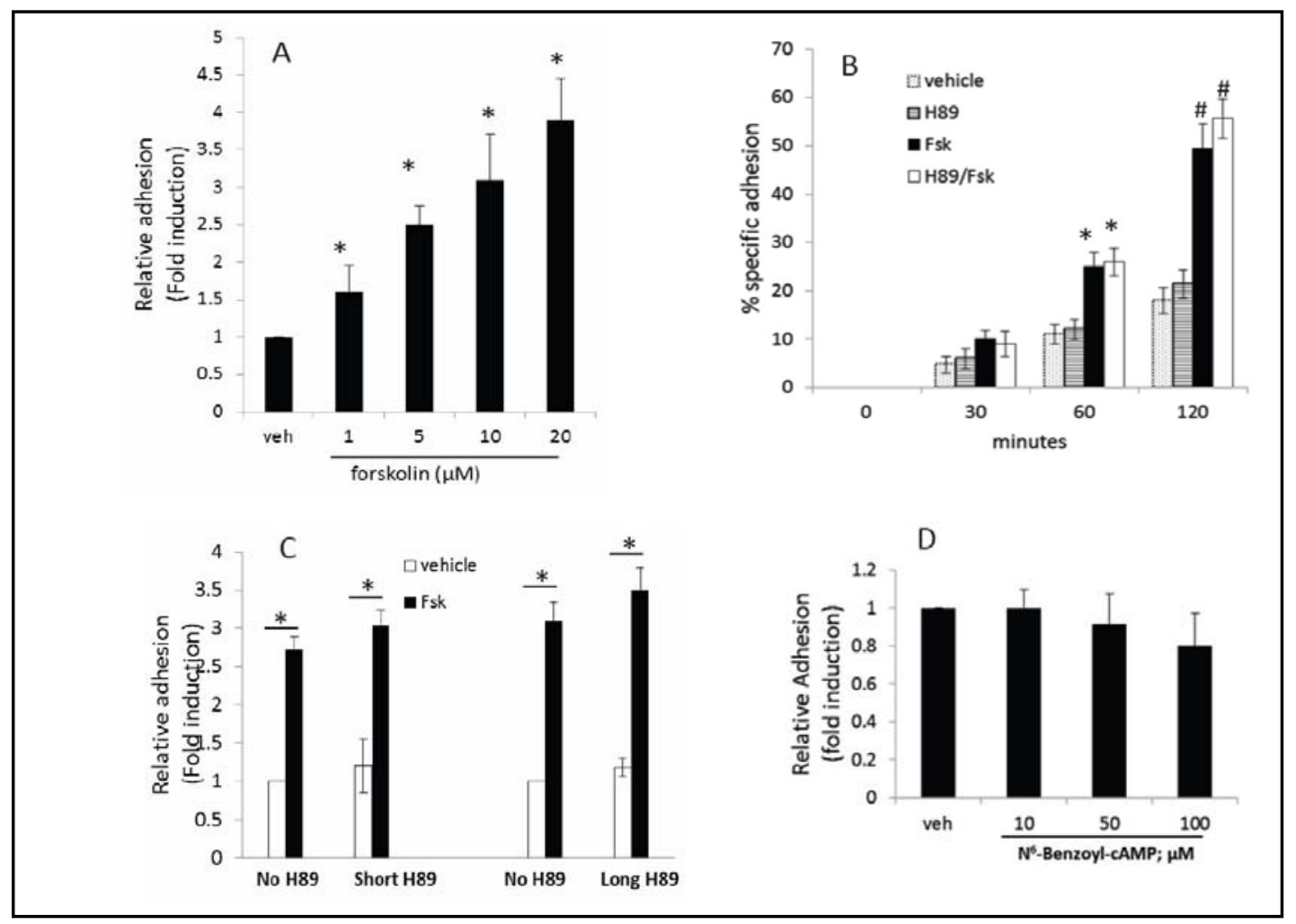

Fig. 1. cAMP induces adhesion of microVSMCs in a PKA-independent fashion. A. Cells were treated with the vehicle DMSO (veh.) or increasing concentrations of forskolin and allowed to adhere for one hour. Adhesion was measured and plotted as relative fold induction over veh-treated cells. Bar represents the mean \pm SEM. * denotes a $p<0.05$ (versus veh). B. Cells were treated with vehicle DMSO (veh.), H89 $(5 \mu \mathrm{M})$, forskolin (fsk; $10 \mu \mathrm{M}$ ) or H89 and fsk together. $\mathrm{H} 89$ is added 30 minutes before cells were allowed to adhere. Adhesion was measured as percent of adhering cells compared to the total input of cells. Bar represents the mean \pm SEM. * denotes a $p<0.05$ (forskolin versus vehicle) and \# a $p<0.001$ (forskolin versus vehicle). C. Cells were incubated with H89 30 minutes before allowing them to adhere (short) or 30 minutes before trypsinization, during the recovery phase and during the seeding period (long). Cells were allowed to adhere for 1 hour in the absence (hollow bars) or presence (solid bars) of forskolin $(10 \mu \mathrm{M})$ and adhesion measured. For either the short or the long incubation periods, a value of 1 was assigned to the vehicle-treated group absent of H89, relative to which the other values were plotted. Bar represents the mean \pm SEM. ${ }^{*}$ denotes a $p<0.05$ (forskolin versus vehicle). D. Cells were treated with DMSO (veh.) or increasing concentrations of $\mathrm{N}^{6}$ Benozyl-cAMP and allowed to adhere for one hour. Adhesion was measured and plotted as relative fold induction over veh-treated cells. Bar represents the mean \pm SEM.

To better determine if PKA activation affects adhesion, cells were treated with $\mathrm{N}^{6}$ Benozyl-cAMP (0-100 $\mu \mathrm{M})$, a cAMP analogue that selectively activates PKA. No significant difference in adhesion to fibronectin was observed between the vehicle or the $\mathrm{N}^{6}$-BenozylcAMP treated cells ( $n=3 ; p>0.05$ for either concentration) (Fig. 1D). This confirms that cAMP promotes adhesion of arteriolar SMCs independently of PKA.

\section{Epac activation potentiates arteriolar SMC adhesion to fibronectin}

We recently reported that the Epac-selective cAMP-analogue 8-(4-Chlorophenylthio)2'-0-methyladenosine 3',5'-cyclic monophosphate (or 8-pCPT-2'-O-Me-cAMP) activates Epac in arteriolar SMCs [10]. Here, we utilized 8-pCPT-2'-0-Me-cAMP to determine the effect of endogenous Epac activation on cell adhesion to fibronectin. Treatment with 8-pCPT-2'-0Me-cAMP induced a concentration- $(0-200 \mu \mathrm{M})$ dependent increase in adhesion (Fig. 2A), with the maximal effect observed at $150 \mu \mathrm{M}$ ( 4.23 fold increase; $\mathrm{n}=3 ; \mathrm{p}<0.01$ ). Similarly, a 


\section{Cellular Physiology $\quad$ Cell Physiol Biochem 2012;30:247-258 and Biochemistry

Fig. 2. Epac activation induces adhesion of microVSMCs. A. Cells were treated with vehicle (veh.) or increasing concentrations of 8-pCPT2'-O-Me-cAMP and allowed to adhere for one hour. Adhesion was measured and plotted as relative fold induction over veh-treated cells. Bar represents the mean \pm SEM. $*$ denotes a $p<0.05$ and \# a $p<0.01$ (versus veh). B. Cells were treated with vehicle (veh.) or $150 \mu \mathrm{M}$ of 8-pCPT-2'-0-Me-cAMP and allowed to adhere for different

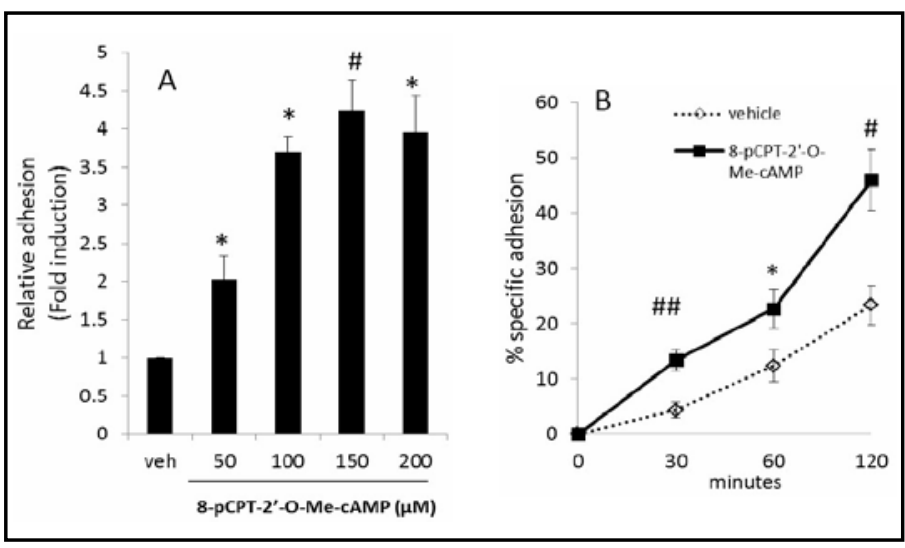
durations. Adhesion was measured as percent of adhering cells compared to the total input of cells. Values represent the mean \pm SEM. ${ }^{*}$ denotes a $p<0.05$, \# a $p<0.01$ and \#\# a $p<0.005$ (versus vehicle).

Fig. 3. Epac is necessary for the cAMP-induced adhesion of microVSMCs to fibronectin. A. Cells were co-transfected with a CMV-luciferase and either a pcDNA3.1 (mock), a wildtype Epac (Epac), or a dominant negative Epac (Epac-DN). 48 hours later, cells were trypsinized, seeded in the absence of presence of forskolin $(10 \mu \mathrm{M})$, and allowed to adhere for 1 hour. Nonadherent cells were washed, and adhesion was determined as percent of adherent cells compared to the total input of cells. Bar represents the mean \pm SEM. ${ }^{*}$ denotes a $p<0.05$.

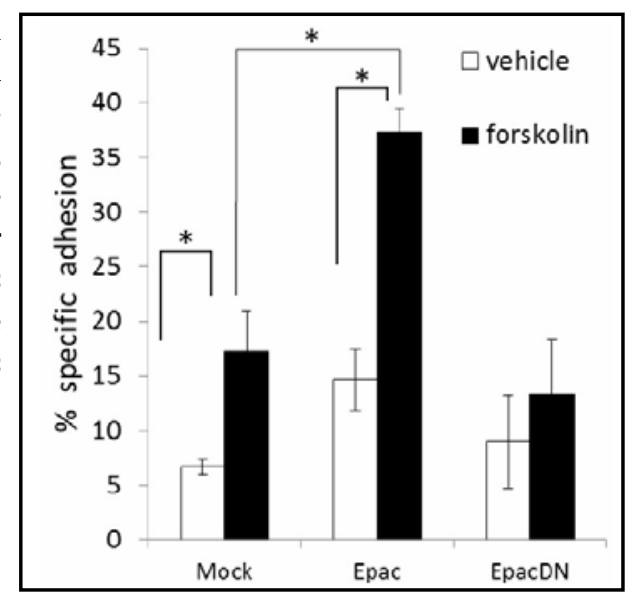

time- (0-120 minutes) dependent increase in the adhesion was observed after treatment with 8-pCPT-2'-0-Me-cAMP compared to vehicle treated cells. This increase was significant at all checked timepoints $(4.3 \%$ vs $13 \%$ after 30 minutes, $n=3, p<0.005 ; 12 \%$ vs $23 \%$ after 60 minutes, $\mathrm{n}=3, \mathrm{p}<0.05 ; 23 \%$ vs $46 \%$ after 120 minutes, $\mathrm{n}=3, \mathrm{p}<0.01$ ).

\section{Epac is necessary and sufficient for cAMP-induced adhesion}

We next wished to determine if Epac expression plays a role in the cAMP-induced adhesion. Cells overexpressing Epac or expressing a dominant negative mutant of Epac (EpacDN) were utilized. Interestingly, even in the absence of forskolin, cells overexpressing Epac exhibited significantly higher adhesion than mock transfectants ( 15 vs $6.7 \%, n-=3, p<0.05$ ) (Fig. 3). This suggests that increased Epac expression is sufficient to potentiate adhesion to fibronectin. On the contrary, cells expressing Epac-DN did not exhibit any increase in adhesion compared to mock-transfectants ( 9 vs 6.7\%, $n=3, p>0.05$ ) (Fig. 3).

In the presence of forskolin, Epac-overexpressing cells exhibited a dramatic increase in adhesion compared to the mock-transfected cells ( 37 vs $17 \%, n=3, p<0.01$ ) (Fig. 3). Forskolintreated Epac-DN transfectants did not exhibit any significant difference in adhesion compared to forskolin-treated mock-transfected cells (13 vs $17 \%, n=3, p>0.05$ ) (Fig. 3). Moreover, there was no significant difference in the adhesion between the vehicle or forskolin-treated EpacDN transfectants (13 vs 9, $n=3, p>0.05$ ). This clearly demonstrates the Epac is necessary for the cAMP-induced adhesion of these cells.

\section{$\beta 1$-integrins mediate the Epac-induced adhesion to fibronectin}

To determine if the cAMP-evoked adhesion is mediated by integrins, cells were incubated in the absence or presence of the integrin-binding peptide, RGD (Arginine, Glycine, Aspartic 


\section{Cellular Physiology and Biochemistry}

Fig. 4. $\beta 1$-integrins mediate the Epac-induced adhesion to fibronectin. Cells were incubated in the absence (control) or presence of the integrin-binding peptide, RGD (Arginine, Glycine, Aspartic acid; +RGD; $100 \mu \mathrm{M}$ ) or an antibody directed against $\beta 1$ integrins (+anti $\beta 1)$. Cells were treated with vehicle (hollow bars), $150 \mu \mathrm{M}$ of 8-pCPT-2'O-Me-cAMP (solid bars) (A), 10 $\mu \mathrm{M}$ forskolin (B) or 1mM 8-Br-cAMP (C) and allowed to adhere for 1 hour. Adhesion was measured and plotted as relative fold induction over vehicle-treated cells. Bar represents the mean \pm SEM. $*$ denotes a $p<0.05$ and \# a $p<0.01$.D. Cells were plated onto poly-L-Lysine coated wells and treated either with vehicle, $150 \mu \mathrm{M} 8$ pCPT-2'-O-Me-cAMP, $10 \mu \mathrm{M}$ forskolin or $1 \mathrm{mM} 8$-Br-cAMP and allowed to adhere for various durations. Nonadherent cells were washed, and adhesion was determined as percent of adhering cells compared to the total input of cells. Values represent the mean \pm SEM.

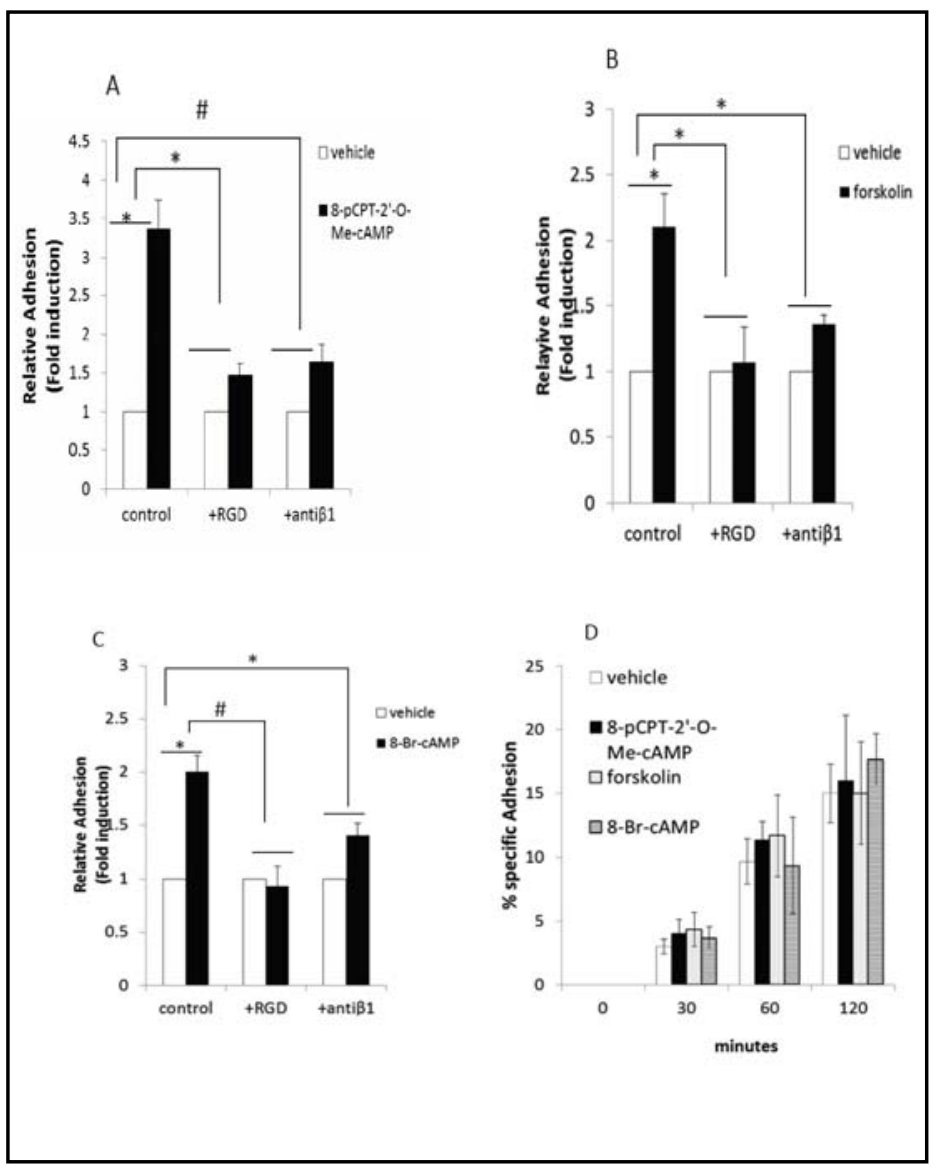

acid; $100 \mu \mathrm{M}$ ), or an antibody directed against $\beta 1$ integrins. The 8-pCPT-2'-0-Me-cAMPpotentiated increase in cell adhesion was significantly diminished when cells were pretreated with RGD ( 3.4 versus 1.5 fold increase, $n=3, p<0.05$ ) or with the $\beta 1$-integrin antibody (3.4 versus 1.6 fold increase, $n=3, p<0.01$ ). Similar results were obtained using forskolin (Fig. 4B) or 8-Br-cAMP (Fig. 4C) instead of 8-pCPT-2'-0-Me-cAMP.

Importantly, when cells were plated onto poly-L-Lysine coated wells, 8-pCPT-2'-O-MecAMP $(150 \mu \mathrm{M})$ failed to significantly affect the adhesion of cells (Fig. 4D, n=3, p>0.05 for all three timepoints). Similar results were obtained with forskolin or 8-Br-cAMP (Fig. 4D). Taken together, these data indicate that the cAMP-induced Epac-mediated adhesion is mediated via integrin binding to extracellular proteins.

Physiologic cAMP-elevating stimulus induces adhesion

We next wished to determine if physiologically relevant stimuli mimic the effects of forskolin or 8-pCPT-2'-0-Me-cAMP. Indeed, stimulation of cells with isoproterenol, a $\beta$-adrenergic receptor agonist, significantly increased adhesion to fibronectin in a concentration- ( 0 to $10 \mu \mathrm{M})$ and time- (0 to 120 mins) dependent fashion. Treatment with $10 \mu \mathrm{M}$ of isoproterenol induced a significant increase in adhesion (4-fold increase compared to vehicle; $\mathrm{n}=3, \mathrm{p}<0.01$ ) (Fig. $5 \mathrm{~A}$ ). Moreover, $1 \mu \mathrm{M}$ isoproterenol significantly increased adhesion after 30,60 and 120 minutes ( 6.2 vs $12 \%, 12$ vs $22 \%$ and 21 vs $38 \%$ adhesion, respectively; $\mathrm{n}=3$ and $\mathrm{p}<0.05$ for either timepoint) (Fig. 5B). This isoproterenol-induced adhesion was not significantly affected by PKA inhibition (Fig 5C). Indeed, pretreatment of cells with $\mathrm{H} 89$ before, during and after the recovery period (long) or only after the recovery period (short) did not affect the isoproterenol-induced adhesion on fibronectin (Fig. 5C). For short treatments, isoproterenol induced a 2.8- or 2.7- fold increase ( $n=3 ; p>0.05)$ in adhesion in the respective absence or presence of H89. In separate experiments with long treatments, 


\section{Cellular Physiology $\quad$ Cell Physiol Biochem 2012;30:247-258

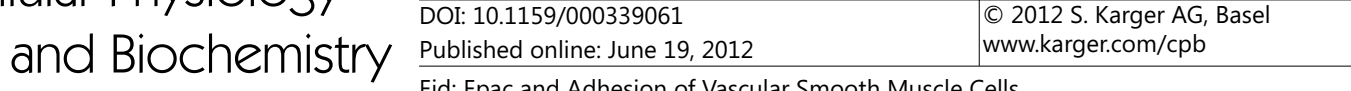 \\ Eid: Epac and Adhesion of Vascular Smooth Muscle Cells}

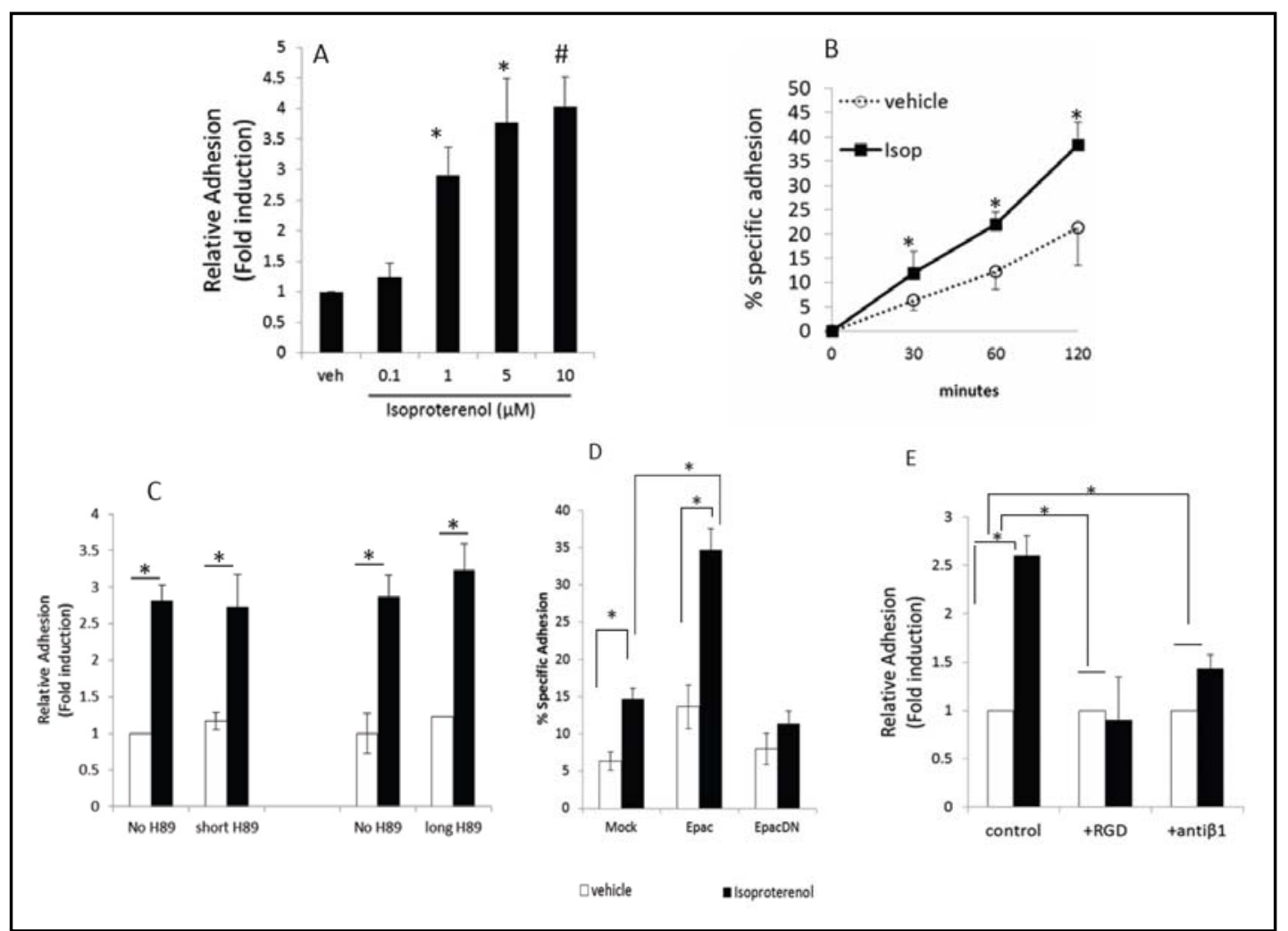

Fig. 5. Isoproterenol induces adhesion of microVSMCs. A. Cells were treated with vehicle (veh.) or increasing concentrations of isoproterenol and allowed to adhere for one hour. Adhesion was measured and plotted as relative fold induction over veh-treated cells. Bar represents the mean \pm SEM. * denotes a $p<0.05$ and \# a $p<0.01$ (versus veh). B. Cells were treated with vehicle or $1 \mu \mathrm{M}$ of isoproterenol (Isop) and allowed to adhere for different durations. Nonadherent cells were washed, and adhesion was measured as percent of adhering cells compared to the total input of cells. Values represent the mean \pm SEM. ${ }^{*}$ denotes a $p<0.05$ (versus vehicle). C. Cells were incubated with H89 30 minutes before allowing them to adhere (short) or 30 minutes before trypsinization, during the recovery phase and during the seeding period (long). Cells were allowed to adhere for 1 hour in the absence (hollow bars) or presence (solid bars) of isoproterenol (Isop; 1 $\mu \mathrm{M})$ and adhesion measured. For either the short or the long incubation periods, a value of 1 was assigned to the vehicle-treated group absent of $\mathrm{H89}$, relative to which the other values were plotted. Bar represents the mean \pm SEM. * denotes a $p<0.05$ (Isop versus veh) . D. Cells were co-transfected with a CMV-luciferase and either a pcDNA3.1 (mock), a wild-type Epac (Epac), or a dominant negative Epac (Epac-DN). 48 hours later, cells were trypsinized, seeded in the absence of presence of isoproterenol (Isop; $1 \mu \mathrm{M}$ ), and allowed to adhere for 1 hour. Nonadherent cells were washed, and adhesion was determined as percent of adherent cells compared to the total input of cells. Bar represents the mean \pm SEM. * denotes a $p<0.05$. E. Cells were incubated in the absence (control) or presence of the integrin-binding peptide, RGD (Arginine, Glycine, Aspartic acid; +RGD; $100 \mu \mathrm{M}$ ) or an antibody directed against $\beta 1$ integrins (+anti $\beta 1)$. Cells were treated with vehicle (hollow bars) or $1 \mu \mathrm{M}$ isoproterenol (solid bars) and allowed to adhere for 1 hour. Adhesion was measured and plotted as relative fold induction over vehicle-treated cells. Bar represents the mean \pm SEM. * denotes a $p<0.05$.

isoproterenol induced a 2.9- or 3.2- fold increase $(p>0.05)$ in adhesion in the respective absence or presence of H89 (Fig. 5C). Taken together, these data suggest that isoproterenol promotes adhesion of arteriolar SMC via a PKA-independent mechanism.

We next wished to verify if Epac expression plays a role in the isoproterenol-induced adhesion. Cells overexpressing Epac or expressing a dominant negative mutant of Epac (Epac-DN) were utilized. In the absence of isoproterenol, cells overexpressing Epac exhibited significantly higher adhesion to fibronectin than mock transfectants (14 vs $6.3 \%, n=3$, 


\section{Cellular Physiology Cell Physiol Biochem 2012;30:247-258

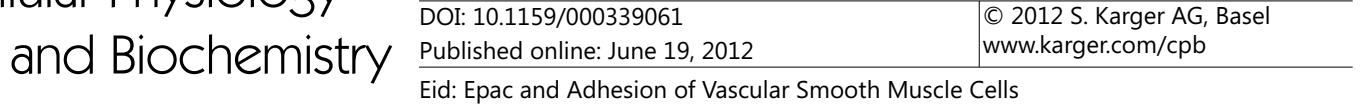

p $<0.05$ ) (Fig. 5D). On the contrary, cells expressing Epac-DN did not exhibit any increase in adhesion compared to mock-transfectants ( 8 vs 6.3\%, n=3, p>0.05) (Fig. 5D).

In the presence of isoproterenol, Epac-overexpressing cells exhibited a dramatic increase in adhesion compared to the mock-transfected cells ( 35 vs $15 \%, n=3, p<0.05$ ) (Fig. 5D). However, isoproterenol-treated Epac-DN transfectants did not exhibit any significant difference in adhesion compared to treated mock-transfectants ( 15 vs $11 \%, n=3, p>0.05$ ) (Fig. 5D). Moreover, isoproterenol failed to cause any significant increase in the adhesion of Epac-DN transfectants ( 11 vs 8, $n=3, p>0.05$ ) (Fig. 5D). This demonstrates that Epac is necessary for the isoproterenol-induced adhesion of these cells.

To determine if the isoproterenol-evoked adhesion was mediated by integrins, cells were incubated in the absence or presence RGD or an antibody directed against $\beta 1$ integrins. As Figure 5E shows, contrary to its effects in significantly $(\mathrm{p}<0.05)$ promoting adhesion in non-treated cells, isoproterenol failed to significantly affect cell adhesion in cells pre-treated with RGD ( 1 versus 0.9 fold increase, $n=3, p>0.05$ ) or the $\beta 1$-integrin antibody ( 1 versus 1.4 fold increase, $n=3, p>0.05$ ).

\section{Discussion}

Despite the critical role of cAMP cardiovascular physiology and pathophysiology, much remains to be understood about its signaling in human arterioles. This is indeed the first report that describes the effect of cAMP-Epac signaling on phenotypic behavior of arteriolar SMCs. Here, we report that cAMP increases adhesion of human arteriolar SMCs to fibronectin via an EPAC-dependent but PKA-independent mechanism. These results were mimicked by isoproterenol, a more physiologically relevant cAMP-elevating agent. More importantly, this is the first report that elucidates a mechanism utilized by arteriolar beta adrenoceptors ( $\beta$-ARs) to induce adhesion to an extracellular matrix protein. Indeed, this report shows that although they can activate both PKA and EPAC pathways, $\beta$-ARs preferentially employ activated EPAC to induce adhesion. We also show that $\beta 1$ integrin mediates the cAMP-evoked adhesion to fibronectin.

Viscoelastic properties of blood vessels are greatly influenced by ECM proteins. Any stimulus that interferes with the delicate and regulated balance of these proteins could affect the size of the vessel lumen, which is directly related to blood flow and pressure $[15,16]$. In vascular SMCs, integrin-mediated adhesion to the ECM's fibronectin induces morphologic and phenotypic changes in vascular SMCs [17-19]. Importantly, integrins are also known to play vital roles in the function, maturity and integrity of blood vessels [19]. This emphasizes the significance of cellular adhesion in cardiovascular physiology and pathophysiology.

A rise in the intracellular cAMP levels is associated with enhanced adhesion to the basement membrane, particularly via an integrin-mediated mechanism [20-23]. The secondary messenger cAMP activates both protein kinase A and the guanine nucleotide exchange factor, Epac $[5,14]$. It is also reported that PKA could mediate cAMP-induced adhesion of vascular smooth muscle cells $[24,25]$. However, these studies were conducted in vascular SMCs isolated from large vessels. Owing to the distinct behavior of vascular SMCs from different vascular beds, it is not safe to extrapolate data from these studies into microvascular SMCs [1, 26, 27]. More importantly, and to the best of our knowledge, a role for Epac in adhesion has not yet been studied in vascular SMCs of any vascular bed.

We first wished to determine if cAMP modulates adhesion of arteriolar SMCs to fibronectin. Indeed, forskolin treatment significantly induced these cells' adhesion to fibronectin, which strongly binds to and activates signaling of beta- 1 integrins. Impressively, this forskolin-stimulated adhesion was not inhibited with $\mathrm{H} 89$ pretreatment, indicating that the forskolin-induced adhesion is mediated via a PKA-independent mechanism. This absence of a PKA involvement could not be due to the lack of activation of PKA by forskolin, since we recently showed that in these cells, forskolin and other cAMP-elevating agents increase 


\section{Cellular Physiology Cell Physiol Biochem 2012;30:247-258

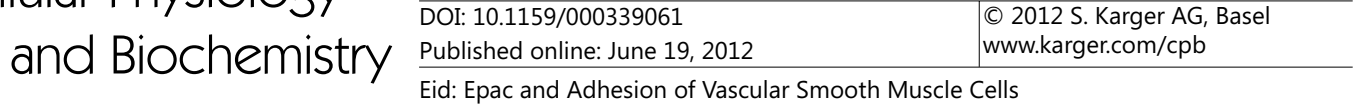

phosphorylation of CREB, a downstream target of PKA [12]. This demonstrates that although PKA is indeed activated in these cells, it does not mediate cAMP-induced adhesion.

It is documented that detachment of cells may activate PKA, a ubiquitous target for cAMP $[28,29]$. This might complicate conclusions based merely on co-treatments with H89 and forskolin after trypsinizing cells for the adhesion assay. If detachment activates PKA, and if a PKA substrate with sustained phosphorylation status is also activated, addition of H89 at a later stage may not signify a PKA independent mechanism. For that reason, we ran additional experiments where $\mathrm{H} 89$ was added prior, during, and after trypsinization (long treatment). The results reported here clearly indicate that the cAMP-induced adhesion to fibronectin was not sensitive to the PKA inhibitor H89. The concentration of H89 used is sufficient to inhibit the forskolin-induced PKA-mediated phosphorylation of CREB, as we recently reported [12].

The observation that cAMP-induced adhesion is indeed PKA-independent prompted the hypothesis that Epac is the mediator for the elicited effect. Indeed, treatment with 8-pCPT-2'0 -Me-cAMP evoked a dramatic increase in the adhesion of cells to fibronectin. Interestingly, the relative increase in adhesion elicited by 8CPT-2Me-cAMP is significantly higher than that evoked by forskolin. Whether this is due to higher potency or affinity of 8CPT-2Me-cAMP than cAMP towards Epac is not clear. However, a similar stronger effect of 8CPT-2Me-cAMP than cAMP on adhesion has been recently reported [30].

The physiologic relevance of our data is demonstrated by the results obtained with isoproterenol as a cAMP-elevating agent. Vascular SMCs express Gs-coupled $\beta$-ARs that are activated by isoproterenol. Our results show that isoproterenol indeed mimicked the effects of cAMP by inducing adhesion to fibronectin via $\beta 1$-integrins in an Epac-mediated but PKAindependent mechanism.

Taken together, these data clearly suggest that $\beta$-ARs, and consequently cAMP, preferentially employ Epac over PKA to induce adhesion to the extracellular fibronectin. This preference may be due to the compartmentalization of $\beta$-ARs with adenylate cyclase and Epac within membrane lipid rafts or cytoplasmic microdomains [31]. More importantly, even though PKA may be activated, its ability to stimulate its downstream targets could be limited by other regulatory mechanisms such as those mediated by scaffolding A-Kinase anchoring proteins (AKAPs) [32]. Given the kinetic differences in the activation of Epac and PKA by cAMP [33], it would not be surprising that vascular SMCs preferentially employ one pathway to regulate their adhesion. Indeed, other mechanisms that selectively employ active Epac rather than active PKA have been previously reported by us and others [12, 34, 35]. However, one cannot exclude the possibility that PKA may still play a role in cAMP-induced adhesion at later time points than the ones investigated in our report.

Integrins play a significant role in the modulation of vascular tone as well as in vascular responses to pressure, flow and vascular injury [7, 36]. Increased adhesion and engagement of integrins could affect distensibility or compliance of blood vessels. This becomes particularly important in resistance-size arteries where a small change in lumen size dramatically impacts blood flow and pressure. It was tempting to speculate that the observed adhesion is indeed mediated by integrins particularly because fibronectin binds to and activates their signaling. Here, we showed that the cAMP-induced Epac-mediated adhesion occurred through $\beta 1$ integrins. Integrin activation can be regulated at different levels like avidity, affinity and/or cell surface expression [37-39]. However, given the short time needed for the cAMP- or Epac-increased adhesion, it is unlikely that an increase in the integrin expression is the underlying cause. Indeed, others have reported that a change in affinity or avidity, rather than expression, underlies the $\beta 1$-integrin-mediated adhesion in response to different stimuli $[40,41]$. However, the exact mechanism underlying the "insideout" activation of integrins, particularly that evoked by cAMP and Epac in vascular SMCs, remains poorly understood and warrants further investigations. 


\section{Cellular Physiology Cell Physiol Biochem 2012;30:247-258 \\ \begin{tabular}{ll|l} 
and Biochemistry & $\begin{array}{l}\text { DOI: 10.1159/000339061 } \\
\text { Published online: June 19, } 2012\end{array}$ & $\begin{array}{l}\text { C 2012 S. Karger AG, Basel } \\
\text { www.karger.com/cpb }\end{array}$ \\
\cline { 2 - 3 } Eid: Epac and Adhesion of Vascular Smooth Muscle Cells
\end{tabular}}

In vascular SMCs, integrin binding to fibronectin increases intracellular levels of guanylate cyclase [42]. Guanylate cyclase activates cGMP-dependent protein kinase (PKG), which is well known to induce vascular relaxation. Integrin activation is also reported to increase sGC content in rat vascular SMCs and potentiates their response to NO donors [43]. Fibronectin has also been recently shown to upregulate PKG in vascular SMCs as well as in aortic walls [7]. More functional studies also show that integrin engagement and activation induces vasodilation of different blood vessels [44-46]. Similarly, activating Epac induces SMC relaxation and vasodilation $[47,48]$. It is therefore tempting to speculate that $\beta$-ARs elicit their vasodilatory effect by activating a cAMP-Epac pathway that promotes increased adhesion to fibronectin. Of the different subtypes expressed in small arteries and arterioles, $\beta 1$-adrenoceptor ( $\beta 1$-AR) appears to be the most likely mediator of $\beta$-AR-mediated vasodilation [49]. However, this remains to be validated.

As such, we hypothesize a model in which $\beta 1$-AR, by raising intracellular levels of cAMP, leads to Epac activation and increased adhesion to fibronectin via $\beta 1$-integrins. This adhesion could then act in an autocrine fashion to increase sGC and PKG content and thus potentiate SMC's responsiveness to NO and NO donors. Further experiments are of course needed to verify the above model.

In summary, this report describes for the first time a role for $\beta$-AR activation in arteriolar SMC adhesion to fibronectin. It is also the first report to demonstrate that in vascular SMCs, cAMP elicits adhesion via Epac rather than PKA-mediated mechanism and that this adhesion is mediated by $\beta 1$ integrins.

\section{Conflict of interest}

None declared.

\section{Acknowledgements}

The author would like to thank the College of Arts and Sciencs at Qatar University for offsetting the publishing costs of this manuscript.

\section{References}

1 Schwartz SM: Smooth muscle migration in atherosclerosis and restenosis. J Clin Invest 1997;100:S87-89.

2 Moiseeva EP: Adhesion receptors of vascular smooth muscle cells and their functions. Cardiovasc Res 2001;52:372-386.

3 Shimizu Y, van Seventer GA, Ennis E, Newman W, Horgan KJ, Shaw S: Crosslinking of the t cell-specific accessory molecules cd7 and cd28 modulates t cell adhesion. J Exp Med 1992;175:577-582.

4 Laudanna C, Campbell JJ, Butcher EC: Elevation of intracellular camp inhibits rhoa activation and integrindependent leukocyte adhesion induced by chemoattractants. J Biol Chem 1997;272:24141-24144.

5 Halvorson MJ, Coligan JE: Enhancement of vla integrin receptor function on thymocytes by camp is dependent on the maturation stage of the thymocytes. J Immunol 1995;155:4567-4574.

6 Dormond 0, Bezzi M, Mariotti A, Ruegg C: Prostaglandin e2 promotes integrin alpha vbeta 3-dependent endothelial cell adhesion, rac-activation, and spreading through camp/pka-dependent signaling. J Biol Chem 2002;277:45838-45846.

7 Chamorro-Jorganes A, Calleros L, Griera M, Saura M, Luengo A, Rodriguez-Puyol D, Rodriguez-Puyol M: Fibronectin upregulates cgmp-dependent protein kinase type ibeta through c/ebp transcription factor activation in contractile cells. Am J Physiol Cell Physiol 2011;300:C683-691. 


\begin{tabular}{|c|c|c|}
\hline & Cell Physiol Biochem 2012;30:247-258 & \\
\hline and Binchemistry & $\begin{array}{l}\text { DOI: 10.1159/000339061 } \\
\text { Published online: June 19, } 2012\end{array}$ & $\begin{array}{l}\text { (c) } 2012 \text { S. Karger AG, Basel } \\
\text { www.karger.com/cpb }\end{array}$ \\
\hline
\end{tabular}

8 de Rooij J, Zwartkruis FJ, Verheijen MH, Cool RH, Nijman SM, Wittinghofer A, Bos JL: Epac is a rap1 guaninenucleotide-exchange factor directly activated by cyclic amp. Nature 1998;396:474-477.

9 Kawasaki H, Springett GM, Mochizuki N, Toki S, Nakaya M, Matsuda M, Housman DE, Graybiel AM: A family of camp-binding proteins that directly activate rap1. Science 1998;282:2275-2279.

10 Eid AH, Chotani MA, Mitra S, Miller TJ, Flavahan NA: Cyclic amp acts through rap1 and jnk signaling to increase expression of cutaneous smooth muscle alpha2c-adrenoceptors. Am J Physiol Heart Circ Physiol 2008;295:H266-272.

11 Eid AH, Maiti K, Mitra S, Chotani MA, Flavahan S, Bailey SR, Thompson-Torgerson CS, Flavahan NA: Estrogen increases smooth muscle expression of alpha2c-adrenoceptors and cold-induced constriction of cutaneous arteries. Am J Physiol Heart Circ Physiol 2007;293:H1955-1961.

12 Chotani MA, Mitra S, Eid AH, Han SA, Flavahan NA: Distinct camp signaling pathways differentially regulate alpha2c-adrenoceptor expression: Role in serum induction in human arteriolar smooth muscle cells. Am J Physiol Heart Circ Physiol 2005;288:H69-76.

13 Mei FC, Qiao J, Tsygankova OM, Meinkoth JL, Quilliam LA, Cheng X: Differential signaling of cyclic amp: Opposing effects of exchange protein directly activated by cyclic amp and camp-dependent protein kinase on protein kinase b activation. J Biol Chem 2002;277:11497-11504.

14 Su B, Mitra S, Gregg H, Flavahan S, Chotani MA, Clark KR, Goldschmidt-Clermont PJ, Flavahan NA: Redox regulation of vascular smooth muscle cell differentiation. Circ Res 2001;89:39-46.

15 Martinez-Lemus LA, Hill MA, Meininger GA: The plastic nature of the vascular wall: A continuum of remodeling events contributing to control of arteriolar diameter and structure. Physiology (Bethesda) 2009;24:45-57.

16 Song W, Ergul A: Type-2 diabetes-induced changes in vascular extracellular matrix gene expression: Relation to vessel size. Cardiovasc Diabetol 2006;5:3.

17 Thyberg J, Hedin U, Sjolund M, Palmberg L, Bottger BA: Regulation of differentiated properties and proliferation of arterial smooth muscle cells. Arteriosclerosis 1990;10:966-990.

18 Hedin U, Bottger BA, Forsberg E, Johansson S, Thyberg J: Diverse effects of fibronectin and laminin on phenotypic properties of cultured arterial smooth muscle cells. J Cell Biol 1988;107:307-319.

19 Abraham S, Kogata N, Fassler R, Adams RH: Integrin beta1 subunit controls mural cell adhesion, spreading, and blood vessel wall stability. Circ Res 2008;102:562-570.

20 Shimizu Y, van Seventer GA, Ennis E, Newman W, Horgan KJ, Shaw S: Crosslinking of the t cell-specific accessory molecules cd7 and cd28 modulates t cell adhesion. J Exp Med 1992;175:577-582.

21 Laudanna C, Campbell JJ, Butcher EC: Elevation of intracellular camp inhibits rhoa activation and integrindependent leukocyte adhesion induced by chemoattractants. J Biol Chem 1997;272:24141-24144.

22 Halvorson MJ, Coligan JE: Enhancement of vla integrin receptor function on thymocytes by camp is dependent on the maturation stage of the thymocytes. J Immunol 1995;155:4567-4574.

23 Dormond 0, Bezzi M, Mariotti A, Ruegg C: Prostaglandin e2 promotes integrin alpha vbeta 3-dependent endothelial cell adhesion, rac-activation, and spreading through camp/pka-dependent signaling. J Biol Chem 2002;277:45838-45846.

24 Bulin C, Albrecht U, Bode JG, Weber AA, Schror K, Levkau B, Fischer JW: Differential effects of vasodilatory prostaglandins on focal adhesions, cytoskeletal architecture, and migration in human aortic smooth muscle cells. Arterioscler Thromb Vasc Biol 2005;25:84-89.

25 Howe AK: Regulation of actin-based cell migration by camp/pka. Biochim Biophys Acta 2004;1692:159174.

26 Schwartz SM: The intima : A new soil. Circ Res 1999;85:877-879.

27 Adams LD, Geary RL, McManus B, Schwartz SM: A comparison of aorta and vena cava medial message expression by cdna array analysis identifies a set of 68 consistently differentially expressed genes, all in aortic media. Circ Res 2000;87:623-631.

28 Howe AK, Juliano RL: Regulation of anchorage-dependent signal transduction by protein kinase a and p21activated kinase. Nat Cell Biol 2000;2:593-600.

29 Howe AK, Hogan BP, Juliano RL: Regulation of vasodilator-stimulated phosphoprotein phosphorylation and interaction with abl by protein kinase a and cell adhesion. J Biol Chem 2002;277:38121-38126.

30 Rangarajan S, Enserink JM, Kuiperij HB, de Rooij J, Price LS, Schwede F, Bos JL: Cyclic amp induces integrinmediated cell adhesion through epac and rap1 upon stimulation of the beta 2-adrenergic receptor. J Cell Biol 2003;160:487-493. 


\begin{tabular}{|c|c|c|}
\hline حمل الإ & Cell Physiol Biochem 2012;30:247-258 & \\
\hline and Binchemistry & $\begin{array}{l}\text { DOI: } 10.1159 / 000339061 \\
\text { Published online: June 19, } 2012\end{array}$ & $\begin{array}{l}\text { (c) } 2012 \text { S. Karger AG, Base } \\
\text { www.karger.com/cpb }\end{array}$ \\
\hline
\end{tabular}

31 Macdougall DA, Agarwal SR, Stopford EA, Chu H, Collins JA, Longster AL, Colyer J, Harvey RD, Calaghan S: Caveolae compartmentalise beta2-adrenoceptor signals by curtailing camp production and maintaining phosphatase activity in the sarcoplasmic reticulum of the adult ventricular myocyte. J Mol Cell Cardiol 2012;52:388-400.

32 Delint-Ramirez I, Willoughby D, Hammond GV, Ayling LJ, Cooper DM: Palmitoylation targets akap79 protein to lipid rafts and promotes its regulation of calcium-sensitive adenylyl cyclase type 8. J Biol Chem 2011;286:32962-32975.

33 Das R, Chowdhury S, Mazhab-Jafari MT, Sildas S, Selvaratnam R, Melacini G: Dynamically driven ligand selectivity in cyclic nucleotide binding domains. J Biol Chem 2009;284:23682-23696.

34 Rampersad SN, Ovens JD, Huston E, Umana MB, Wilson LS, Netherton SJ, Lynch MJ, Baillie GS, Houslay MD, Maurice DH: Cyclic amp phosphodiesterase $4 \mathrm{~d}$ (pde4d) tethers epac1 in a vascular endothelial cadherin (ve-cad)-based signaling complex and controls camp-mediated vascular permeability. J Biol Chem 2010;285:33614-33622.

35 Qin Y, Stokman G, Yan K, Ramaiahgari S, Verbeek F, de Graauw M, van de Water B, Price LS: Camp signalling protects proximal tubular epithelial cells from cisplatin-induced apoptosis via activation of epac. $\mathrm{Br} \mathrm{J}$ Pharmacol 2012;165:1137-1150.

36 Waitkus-Edwards KR, Martinez-Lemus LA, Wu X, Trzeciakowski JP, Davis MJ, Davis GE, Meininger GA: Alpha(4)beta(1) integrin activation of l-type calcium channels in vascular smooth muscle causes arteriole vasoconstriction. Circ Res 2002;90:473-480.

37 Carman CV, Springer TA: Integrin avidity regulation: Are changes in affinity and conformation underemphasized? Curr Opin Cell Biol 2003;15:547-556.

38 Brakebusch C, Bouvard D, Stanchi F, Sakai T, Fassler R: Integrins in invasive growth. J Clin Invest 2002;109:999-1006.

39 Kim C, Ye F, Ginsberg MH: Regulation of integrin activation. Annu Rev Cell Dev Biol 2011;27:321-345.

40 Seki J, Koyama N, Kovach NL, Yednock T, Clowes AW, Harlan JM: Regulation of beta1-integrin function in cultured human vascular smooth muscle cells. Circ Res 1996;78:596-605.

41 Kappert K, Schmidt G, Doerr G, Wollert-Wulf B, Fleck E, Graf K: Angiotensin ii and pdgf-bb stimulate beta(1)-integrin-mediated adhesion and spreading in human vsmcs. Hypertension 2000;35:255-261.

42 Diez-Marques ML, Ruiz-Torres MP, Griera M, Lopez-Ongil S, Saura M, Rodriguez-Puyol D, Rodriguez-Puyol M: Arg-gly-asp (rgd)-containing peptides increase soluble guanylate cyclase in contractile cells. Cardiovasc Res 2006;69:359-369.

43 Ruiz-Torres MP, Griera M, Chamorro A, Diez-Marques ML, Rodriguez-Puyol D, Rodriguez-Puyol M: Tirofiban increases soluble guanylate cyclase in rat vascular walls: Pharmacological and pathophysiological consequences. Cardiovasc Res 2009;82:125-132.

44 Raffetto JD, Barros YV, Wells AK, Khalil RA: Mmp-2 induced vein relaxation via inhibition of [ca2+]edependent mechanisms of venous smooth muscle contraction. Role of rgd peptides. J Surg Res 2010;159:755-764.

45 Hein TW, Platts SH, Waitkus-Edwards KR, Kuo L, Mousa SA, Meininger GA: Integrin-binding peptides containing rgd produce coronary arteriolar dilation via cyclooxygenase activation. Am J Physiol Heart Circ Physiol 2001;281:H2378-2384.

46 Quan A, Ward ME, Kulandavelu S, Adamson SL, Langille BL: Endothelium-independent flow-induced dilation in the mouse carotid artery. J Vasc Res 2006;43:383-391.

47 Sukhanova IF, Kozhevnikova LM, Popov EG, Podmareva ON, Avdonin PV: Activators of epac proteins induce relaxation of isolated rat aorta. Dokl Biol Sci 2006;411:441-444.

48 Zieba BJ, Artamonov MV, Jin L, Momotani K, Ho R, Franke AS, Neppl RL, Stevenson AS, Khromov AS, Chrzanowska-Wodnicka M, Somlyo AV: The camp-responsive rap1 guanine nucleotide exchange factor, epac, induces smooth muscle relaxation by down-regulation of rhoa activity. J Biol Chem 2011;286:1668116692.

49 Briones AM, Daly CJ, Jimenez-Altayo F, Martinez-Revelles S, Gonzalez JM, McGrath JC, Vila E: Direct demonstration of beta1- and evidence against beta2- and beta3-adrenoceptors, in smooth muscle cells of rat small mesenteric arteries. Br J Pharmacol 2005;146:679-691. 